\title{
The role of informal digital learning of English and a high- stakes English test on perceptions of English as an international language
}

\author{
Ju Seong Lee \\ The Education University of Hong Kong
}

\begin{abstract}
This study investigated the relationship among informal digital learning of English (IDLE) practice, a high-stakes English test, English productive skills, and perceptions of English as an international language (EIL). Eighty-nine English as a foreign language (EFL) undergraduate students across three South Korean cities participated in the study. The participants submitted their scores in the Test of English for International Communication (TOEIC, South Korea's most popular high-stakes English test), took English speaking and productive vocabulary-level tests, and completed surveys that measured the frequency of their IDLE activities and EIL perceptions. Results of the hierarchical multiple regression analyses showed that IDLE practice and TOEIC scores were significant predictors of EIL perceptions. The structural equation modelling analysis further revealed that IDLE practice partially mediated the relationship between TOEIC scores and EIL perceptions. This indicates that students with higher TOEIC scores tended to practise IDLE activities more frequently, which enabled them to experience diverse accents and users of English and, in turn, help increase their EIL perceptions. It also suggests that more proficient EFL speakers may not necessarily become competent EIL users. These findings are discussed with consideration of South Korea's socio-educational contexts, followed by pedagogical implications for English language educators and test developers.
\end{abstract}

Implications for practice or policy:

- Policy makers and school leaders should recognise that IDLE activities and high-stakes international English tests, such as TOEIC, could enhance EFL learners' EIL perceptions.

- Teachers can encourage EFL students to develop and implement their own IDLE activities based on their learning interests and the availability of digital devices and resources.

- $\quad$ Test developers (e.g., Educational Testing Service) are encouraged to make continuous efforts to include various English accents into high-stakes international English listening tests, such as TOEIC.

Keywords: informal digital learning of English, high-stakes English test, English as an international language, English speaking, productive vocabulary knowledge

\section{Introduction}

In today's multilingual and multicultural world, it is increasingly common for individuals to perform various personal and professional activities in English across linguistically and culturally diverse environments. This phenomenon has been observed around the world in aged care homes, hospitals, private companies, business schools, university e-learning systems, language learning online communities, and social media environments (Benson, 2015; Friedman, 2005; Gillham et al., 2018; Popescu \& Warmenhoven, 2019; Rosen et al., 2004; Xu, 2017). In the field of teaching English to speakers of other languages (TESOL), English language teaching researchers and practitioners have consistently shed light on this changing sociolinguistic landscape (Galloway \& Rose, 2015; Jenkins, 2005; Kachru, 1985; Matsuda, 2002, 2012, 2017, 2018; McKay, 2002, 2018; Sharifian, 2009; Smith, 1976). These professionals have also challenged traditional models of TESOL pedagogy (e.g., having English as a foreign-language [EFL] students become exclusively exposed to American English accents and usages), as they seem to occur isolated from the real-world work contexts that students are likely to encounter upon graduation (e.g., South Korean [hereafter Korean] engineers collaborating virtually with colleagues from India and China in English; Matsuda, 2017). Consequently, under the framework of 
English as an international language (EIL), which underscores a functional aspect of English learning (Matsuda, 2018), practitioner-oriented TESOL scholars have incorporated EIL perspectives into pedagogy (Matsuda, 2012, 2017). Concurrently, major test developers (e.g., Educational Testing Service [ETS]) have also begun to integrate EIL perspectives into high-stakes international English tests such as the Test of English for International Communication (TOEIC) (Elder \& Harding, 2008; Kang, Moran, \& Thomson, 2019).

Given the digital and social media booms and their widespread application for second language (L2) learning, contemporary EFL students are increasingly practising English in a range of extramural digital contexts (aka informal digital learning of English [IDLE]; Lee, 2019; Sauro \& Zourou, 2019; Sockett \& Toffoli, 2012; Sylvén \& Sundqvist, 2017). IDLE activities have been found to be positively linked with TOEIC scores (Lee, 2019), English productive skills, such as English speaking (Lee, 2019; Lee \& Dressman, 2018) and productive vocabulary knowledge (Lee, 2019; Lee \& Dressman, 2018; Sundqvist, 2019; Sundqvist \& Sylvén, 2014), and EIL perceptions (Lee \& Lee, 2019b).

Literature indicates that contemporary EFL learners are increasingly interacting with diverse English users in IDLE settings (Chen, 2012; Lee \& Lee, 2019b). Additionally, major test developers, such as ETS, have recently integrated EIL perspectives into high-stakes international English tests (e.g., TOEIC) by including Australian and British accents to the listening tests (Kang et al., 2019; Ke, 2019). Furthermore, in several EFL countries TOEIC scores, along with English productive skills, are generally indicative of one's global mindset as well as skillful use of cross-cultural communication strategies (Oliveri \& Tannenbaum, 2017). To date, however, there is no empirical research that investigates altogether the relationship among IDLE practice, high-stakes international English test (TOEIC scores), English productive levels (English speaking and productive vocabulary levels), and EIL perceptions among contemporary EFL learners. In addition, while prior research has reported a link between TOEIC score and IDLE practice (Lee, 2019; Tagashira et al., 2010), IDLE practice and EIL perception (Lee \& Lee, 2019a, 2019b), and TOEIC score and EIL perception (Oliveri \& Tannenbaum, 2017), it remains to be seen whether IDLE practice plays a mediating role in the relationship between TOEIC scores and perceptions of EIL. The current study aimed to address these research gaps in the literature. The findings of this study will advance our current knowledge about IDLE and EIL. They will also provide pedagogical implications for TESOL educators and test developers, which can help English learners function more effectively as competent English users in today's interconnected global arena.

\section{Literature review}

\section{IDLE}

With the advancements and educational affordances of digital technologies, contemporary L2 learners are increasingly practising their target language via a range of extramural digital contexts (Godwin-Jones, 2018; Richards, 2015; Sylvén \& Sundqvist, 2017). Lee (2019) referred to this phenomenon as IDLE, which is defined as learning English autonomously in extramural digital contexts independent of formal English instruction. For example, a Korean EFL student interacts casually with other English users from Australia and Japan on social media for socialising, an activity that is not organised or assessed by his or her formal language instructor. A rapidly growing amount of research attention has been shifted to this emerging phenomenon, using several similar concepts such as online informal learning of English (Jurkovič, 2019; Kusyk, 2017; Sockett \& Toffoli, 2012), extramural English (Jensen, 2017; Sundqvist \& Sylvén, 2016), fully autonomous self-instructed learners (Cole \& Vanderplank, 2016), out-of-class autonomous language learning with technology (C. Lai, 2017), informal second language learning (Arndt \& Woore, 2018), and computer-assisted language learning in the digital wilds (Sauro \& Zourou, 2019). Although this strand of computer-assisted language learning inquiry is still considered in an early stage (C. Lai, 2017), studies have provided empirical evidence linking L2 learning in extramural digital environments with positive psychological aspects of English learning, such as motivation (C. Lai, 2019; Sundqvist \& Sylvén, 2014) and confidence (C. Lai, Zhu, \& Gong, 2015). Research also indicates that IDLE-oriented activities have positive consequences for improving students' performance on grammar (Cole \& Vanderplank, 2016), standardised English tests such as TOEIC (Lee, 2019), speaking (Lee \& Dressman, 2018), and productive vocabulary knowledge (Lee, 2019; Lee \& Dressman, 2018; Sundqvist, 2019; Sundqvist \& Sylvén, 2014). 
Concurrently, rapidly emerging technologies (e.g., social media, language learning apps, virtual reality) have made it easier for EFL learners to interact virtually with diverse users of English around the world (Benson, 2015; Chen, 2012; Lee \& Lee, 2019b; Rohrbach, 2018). Using the concept of IDLE, Lee and Lee (2019a, 2019b) have observed this among tech-savvy Korean EFL students and explored the possible relationship between their IDLE practices and EIL perceptions. For example, Lee and Lee (2019a) quantitatively found that the more frequently Korean EFL university students practise English in extramural digital contexts on their own initiative (e.g., talking with various English users online), the more positive they become about using different varieties of English as well as becoming more positive about their ability to employ cross-cultural communication skills. In a mixed-methods follow-up study, Lee and Lee (2019b) have provided qualitative results that illustrate how Korean EFL students' perceptions of various English accents (e.g., English spoken by Indian, Filipino, Vietnamese, Germany, and Russian people) become more positive and their perceived ability to adopt effective cross-cultural communication increases through their engagement in practising a range of IDLE activities. These examples included watching Bollywood movies and socialising with international friends or acquaintances via social media and massive multiplayer online role-playing games.

\section{EIL}

Matsuda (2017) defined EIL as "a function that English performs in international, multilingual contexts, to which each speaker brings a variety of English that they are most familiar with, along with their own cultural frames of reference, and employs various strategies to communicate effectively" (p. xiii). This definition implies that English users need to demonstrate tolerance or acceptance of different English accents and employ effective cross-cultural communication strategies (e.g., behaving appropriately according to interlocutors' cultural backgrounds). These skills are necessary since these users are likely to interact with diverse interlocutors who express various forms of English accents (e.g., English spoken by Australian or Korean people) and cultural values (e.g., Western and Oriental cultures). Several TESOL professionals, albeit with different terminologies and theoretical and intellectual orientations (e.g., English as a Lingua Franca, Global Englishes, and World Englishes; see Matsuda, 2017, 2018; McKay, 2018, for a detailed discussion), have further emphasised that TESOL practice should reflect the current landscape of English language for preparing students to become competent EIL users.

Consequently, at an instructional level, EIL pedagogies have been put into practice through a student-led presentation on various EIL-related topics (Galloway \& Rose, 2018), English communication with diverse English speakers in in-class (Ates, Eslami, \& Wright, 2015; Galloway \& Rose, 2013), out-ofclass (Sung, 2018), and digital settings (Ke \& Cahyani, 2014; Ke \& Suzuki, 2011), and EIL-informed flipped classroom by means of a mobile application (Bozoglan \& Gok, 2017), computer-mediated communication (Hsu \& Beasley, 2019; Wang, 2011), video-sharing platforms (Ates et al., 2015), and blogging (Tanghe, 2014). These intervention studies have generally indicated that these approaches help students improve their perceptions of English varieties and cross-cultural communication skills in face-toface and digital settings.

\section{High-stakes international English tests and EIL}

ETS has constantly worked to integrate EIL perspectives into international English tests, such as TOEIC, by adding different accents (e.g., American, Australian, British, and Canadian) to the listening tests (Choi, 2008; Kang et al., 2019; Ke, 2019) and fund research projects on the effect of diverse English accents on listening test scores (Major, Fitzmaurice, Bunta, \& Balasubramanian, 2002, 2005; Kang et al., 2019; also see Elder \& Harding, 2008). The current ETS official home page also asserts that people who take TOEIC tests can demonstrate "[their] English communication skills needed in today's global workplace ... organizations can be confident they are using a test that measures a range of skills relevant and necessary for success in global workplace communications" (ETS, 2018c). Employers in multinational businesses, such as Shanghai Expo in mainland China (Oliveri \& Tannenbaum, 2017) and multinational military units, such as the Joint Security Area between North and South Korea (International Communication Foundation, 2005) have adopted TOEIC tests to select potential professionals who have global mindsets and who seek to improve their cross-cultural communication skills. 
In recent years, some criticisms have been raised concerning its validity (e.g., a mismatch between TOEIC scores and communicative skills in real-life situations) and its misuse in the workplace (e.g., TOEIC scores being used to gauge employees' levels of effort rather than communication abilities; Choi, 2008; Kobayashi, 2018; Kubota, 2011; J. S.-Y. Park, 2011). Nonetheless, two benefits of TOEIC pertaining to EIL perceptions seem plausible based on previous studies. First, English learners who study with TOEIC preparation materials can become massively exposed to diverse English accents - though still limited to inner circle varieties (e.g., English being used as the native language; Kachru, 1985)which could lead to becoming more open-minded about different English accents and speakers (Choi, 2008; Ke, 2019). In addition, TOEIC test takers intensively prepare for this high-stakes English test using technology in informal settings (e.g., IDLE) in order to obtain higher scores (ETS, 2018a; Hong, Kim, \& Bae, 2017; In'nami \& Koizumi, 2017; Jee \& Kim, 2013; Lee, 2019; Tagashira et al., 2010). In the process of engaging in IDLE activities, they tend to encounter various authentic English accents expressed in a range of digital environments (Lee \& Lee, 2019b).

Literature suggests that IDLE practice is closely associated with learners' TOEIC scores, English productive skills, and EIL perceptions. However, I know of no study that has investigated the association among IDLE practice, TOEIC scores, English productive skills (English speaking and productive vocabulary levels) and EIL perceptions among contemporary EFL learners. In particular, TOEIC, which indirectly measures one's English communicative skills in a cross-cultural situation (Kim, 2018), seems to allow test-takers to experience various English accents and speakers through its preparation materials and additional authentic digital resources, thereby enhancing users' EIL perceptions (Lee, 2019; Lee \& Lee, 2019b; Tagashira et al., 2010). At the same time, there is a scarcity of empirical evidence to sustain this claim; that is, IDLE practice mediates the relationship between TOEIC scores and perceptions of EIL. Therefore, to advance our current knowledge on IDLE and EIL, this study aimed to examine the following research questions:

(1) Are IDLE practice, a high-stakes English test, and productive English skills associated with EFL university students' EIL perceptions?

(2) Does IDLE practice play a mediating role in the relationship between TOEIC scores and perceptions of EIL?

\section{Methods}

\section{Participants and context}

Based on the purposeful sampling strategy, 89 undergraduate EFL students (67.4\% were females), who had practised IDLE activities on a regular basis and had taken TOEIC tests during 2014-2016 were selected. These participants were recruited from nine classes across three major Korean cities. They included English $(n=50 ; 56.2 \%)$ and non-English-majors $(n=39 ; 43.8 \%)$. Their mean age was 21.67 $(S D=1.98)$ and ranged from 19 to 27 . The participants consisted of first-year $(n=28 ; 31.5 \%)$, secondyear $(n=35 ; 39.3 \%)$, third-year $(n=12 ; 13.5 \%)$, and fourth-year students $(n=14 ; 15.7 \%)$. Sixty-seven students $(75.3 \%)$ had no overseas experience, while 19 students $(21.3 \%)$ had 1 to 2 years, and three students $(3.4 \%)$ had more than 2 years.

\section{Instruments}

A questionnaire and English proficiency tests were employed for data collection. The questionnaire consisted of three sections: In Section 1, Lee and Lee's (2019a) EIL perception scale was used to assess participants' two dimensions of EIL (perceptions of English varieties and strategies for cross-cultural communication). Respondents rated its items using a 5-point Likert scale from $1=$ strongly disagree to 5 = strongly agree. Items for IDLE (Section 2) were developed with reference to Lee (2019) and Lee and Lee $(2019 b)$, using a 5 -point Likert scale from $1=$ never to $5=$ very often (many times per day). The construct validity for EIL ( 8 items, factor loadings ranging from .61 to .78) and IDLE (6 items, factor loadings ranging from .66 to .88) was assessed through exploratory factor analysis using the principal axis factor analysis technique with the varimax rotation method (Hair, Anderson, Tatham, \& Black, 1998). The eigenvalue of the two-factor structure was 2.25 , which accounted for $60.09 \%$ of the common variance. The internal reliability for EIL $(\alpha=.90)$ and IDLE $(\alpha=.92)$ was also examined by means of 
Cronbach's alpha $(\alpha)$. Section 3 was designed to collect students' demographic information, such as gender, age, academic year, major, and overseas experience, as well as TOEIC score.

As regards English proficiency tests, productive language outcomes such as the English-speaking test and the Productive Vocabulary Levels Test (PVLT) were administered. Specifically, English speaking tests were individually administered to all 89 participants for 5 minutes apiece. The prompts asked about the interviewees' personal opinions and experiences such as their hobbies, and English learning strategies and motivations to learn English (e.g., What is your motivation for learning English?). Since the speaking test was interactive in nature, I asked follow-up questions according to the interviewee's responses (e.g., Can you tell me how you study English?). Later, after a brief training session, three test raters (one certified rater and two in-service English teachers who were not connected to the sample universities) evaluated all speaking samples in terms of delivery, language use, and topic development in light of a modified version of the TOEFL Speaking Rubrics, which contain detailed and articulated score descriptors (ETS, 2018b). Subsequently, inter-rater reliability was checked using the Intraclass Correlation Coefficient (ICC), and judged acceptable (ICC $=.83, p<.001$ among the three raters) (Shrout \& Fleiss, 1979). To assess another productive language outcome, participants were asked to take the PVLT in a classroom setting for 10 minutes (Laufer \& Nation, 1999; B. Park, 2012). The test contained 18 questions from the University Word List, and students filled in the blanks with a correct word while considering the remaining letters and contextual information. For instance, when students encountered the sentence "It's difficult to ass a person's true knowledge by one or two tests", they could enter "ess" in the blank.

\section{Data collection}

After permissions had been obtained from the Institutional Review Board, three universities, and nine instructors, the potential participants were informed of the research purpose, significance, and ethics. I also thoroughly explained the concept of IDLE using relevant examples (see Table 1) to minimise participants' confusion between formal and informal language learning with technology (C. Lai, 2017). Students voluntarily signed the consent forms. I administered the English speaking tests extramurally, but the instructors and I supervised the survey and PVLT in a classroom setting.

\section{Data analysis}

Four steps were taken to analyse the data using the IBM SPSS Statistics 25 and IBM SPSS Amos 22 programs. First, descriptive statistics were calculated before performing the main analyses. Second, Pearson's correlations were analysed. Third, hierarchical multiple regression analyses were conducted to examine the predictive power of IDLE practice, TOEIC score, English speaking level, and PVLT on EIL perception. Specifically, EIL perception was entered as the dependent variable; demographic data (gender, age, grade, major, and overseas experience) were entered as the first block of variables in order to control for their potential influence on EIL perception; IDLE as the second; and TOEIC score, English speaking level, and PVLT as the third. Finally, structural equation modelling was employed to further examine the relationship among these variables.

\section{Results}

\section{Descriptive statistics}

Values of skewness and kurtosis for EIL perception and IDLE practice were within the acceptable range between -2 and 2, which showed that the data were normally distributed (Finch \& West, 1997). In general, as presented in Table 1, participants gave positive ratings for EIL (the mean scores ranged from 3.15 to 4.01). This suggests that respondents tended to hold positive perceptions of different varieties of English, and they perceived their ability to employ appropriate cross-cultural communication strategies in a positive manner. Table 1 also shows that participants engaged in productive IDLE activities at least once a week (the mean scores ranging from 1.98 to 2.44). Scores in TOEIC $(M=727.39, S D=197.75$, ranging from 200 to 990$)$, speaking $(M=76.45, S D=13.07$, ranging from 55 to 100$)$, and PVLT ( $M=$ $41.40, S D=25.09$, ranging from 8 to 94 ) were widely distributed among the students. 
Table 1

Results of the mean and standard deviation $(N=89)$

\begin{tabular}{|c|c|c|}
\hline & Items & $M(S D)$ \\
\hline \multirow[t]{8}{*}{ EIL } & $\begin{array}{l}\text { 1. Different varieties of English, such as Hong Kong English, Indian English, and } \\
\text { Singaporean English, are acceptable today. }\end{array}$ & $3.74(1.14)$ \\
\hline & $\begin{array}{l}\text { 2. Teachers can use English listening materials that are recorded by people who } \\
\text { have different varieties of English accents. }\end{array}$ & $3.65(1.01)$ \\
\hline & $\begin{array}{l}\text { 3. Different varieties of English, such as Indonesian English, Taiwanese English, } \\
\text { and Japanese English, are acceptable today. }\end{array}$ & $3.56(1.11)$ \\
\hline & $\begin{array}{l}\text { 4. Teachers can include the interaction between non-native and non-native English } \\
\text { speakers (e.g., Indonesian-Japanese speakers) in English listening materials. }\end{array}$ & $3.43(1.13)$ \\
\hline & $\begin{array}{l}\text { 5. I can adjust my conversational style according to my interactions with people } \\
\text { from other cultural backgrounds. }\end{array}$ & $3.44(1.10)$ \\
\hline & $\begin{array}{l}\text { 6. I can explain my own culture and customs clearly in English to people from other } \\
\text { cultures. }\end{array}$ & $3.15(1.18)$ \\
\hline & $\begin{array}{l}\text { 7. I am open-minded in accepting speaking/pronunciation patterns that are different } \\
\text { from those of my home country. }\end{array}$ & $4.01(1.01)$ \\
\hline & 8. I can behave appropriately according to English users I speak with. & $3.49(1.09)$ \\
\hline \multirow[t]{6}{*}{ IDLE } & $\begin{array}{l}\text { 1. I use technology to connect with native speakers of the language (e.g., American, } \\
\text { British). }\end{array}$ & $2.10(1.19)$ \\
\hline & $\begin{array}{l}\text { 2. I use technology to connect with non-native speakers of English all over the } \\
\text { world (e.g., Japanese, Chinese). }\end{array}$ & $1.98(1.19)$ \\
\hline & $\begin{array}{l}\text { 3. I use technology to help myself better understand and appreciate the target } \\
\text { culture. }\end{array}$ & $2.44(1.24)$ \\
\hline & $\begin{array}{l}\text { 4. I use technology to help myself to increase my ability to interact with the target } \\
\text { culture. }\end{array}$ & $2.34(1.30)$ \\
\hline & 5. I talk online in English with English users (e.g., American, British, Korean). & $2.10(1.12)$ \\
\hline & 6. I write to communicate with others online (e.g., sending email, chatting via SNS). & $2.20(1.13)$ \\
\hline
\end{tabular}

\section{Correlation analysis}

EIL perceptions correlated positively with IDLE, TOEIC, speaking, and PVLT at a significant level $(p<$ $.01)$. In particular, EIL perceptions had higher correlations with TOEIC scores $(r=.56 ; p<.01)$ than speaking $(r=.40 ; p<.01)$ and PVLT $(r=.40 ; p<.01)$ (Table 2$)$.

Table 2

Correlations among the variables of interest

\begin{tabular}{|c|c|c|c|c|c|}
\hline & 1 & 2 & 3 & 4 & 5 \\
\hline (1) EIL & - & $.44 *$ & $.56^{*}$ & $.40^{*}$ & $.40^{*}$ \\
\hline (2) IDLE & & - & $.40^{*}$ & $.30 *$ & $.28 *$ \\
\hline (3) TOEIC & & & - & $.52 *$ & $.65^{*}$ \\
\hline (4) Speaking & & & & - & $.61 *$ \\
\hline (5) PVLT & & & & & - \\
\hline
\end{tabular}

Notes. PVLT $=$ Productive Vocabulary Language Test

$* p<.01$

\section{Regression statistics}

Results of the hierarchical multiple regression analysis (Table 3) showed that in Step 1, a student's major $(\beta=-.40, p<.01)$ explained $27 \%$ of the variance in EIL at a significant level $(F[5,83]=6.14, p<.01)$. Adding IDLE in Step 2 improved the model, and a student's major $(\beta=-.34, p<.01)$ and IDLE $(\beta=.32$, $p<.01)$ explained $35 \%$ of the variance in EIL $(F[6,82]=7.43, p<.01)$. In Step 3 , adding TOEIC, speaking, and PVLT significantly improved the model, which explained $43 \%$ of variance in EIL perceptions $(F[9,79]=6.51, p<.01)$. In this model, TOEIC $(\beta=.33, p<.05)$ and IDLE $(\beta=.24, p<$ $.05)$ contributed significantly as predictor variables, while a student's particular major was no longer a significant predictor of EIL perceptions. 
Table 3

Hierarchical regression of IDLE, TOEIC, and English productive skills on EIL perceptions

\begin{tabular}{|c|c|c|c|c|c|c|}
\hline \multirow[t]{2}{*}{ Predictor } & \multicolumn{2}{|c|}{ Step 1} & \multicolumn{2}{|c|}{ Step 2} & \multicolumn{2}{|c|}{ Step 3} \\
\hline & $\mathrm{B}(S E)$ & $\beta$ & $\mathrm{B}(S E)$ & $\beta$ & $\mathrm{B}(S E)$ & $\beta$ \\
\hline Gender & $.15(.21)$ & .81 & $.10(.20)$ & .06 & $.11(.19)$ & .06 \\
\hline Age & $-.07(.06)$ & -.17 & $-.07(.06)$ & -.17 & $-.07(.06)$ & -.16 \\
\hline Grade & $.17(.11)$ & .20 & $.11(.10)$ & .14 & $.09(.10)$ & .11 \\
\hline Major & $-.23(.06)$ & $-.40 * *$ & $-.20(.06)$ & $-.34 * *$ & $-.10(.07)$ & -.18 \\
\hline Overseas experience & $.13(.11)$ & .11 & $.03(.11)$ & .02 & $-.02(.11)$ & -.02 \\
\hline IDLE & & & $.26(.08)$ & $.32 * *$ & $.20(.08)$ & $.24 *$ \\
\hline TOEIC & & & & & $.00(.00)$ & $.33 *$ \\
\hline Speaking & & & & & $.01(.01)$ & .13 \\
\hline PVLT & & & & & $-.00(.01)$ & -.10 \\
\hline$\overline{R^{2}}$ & \multirow{2}{*}{\multicolumn{2}{|c|}{.27}} & \multicolumn{2}{|c|}{.35} & \multicolumn{2}{|c|}{.43} \\
\hline$\Delta R^{2}$ & & & \multicolumn{2}{|c|}{.08} & \multicolumn{2}{|c|}{.08} \\
\hline
\end{tabular}

Notes. $\Delta R^{2}=$ Change of $R^{2} ; \beta=$ Beta. For Major, 1 is English major and 2 is non-English-majors. ${ }^{*} p<.05 ; * *<.01$

To answer the second research question, based on previous studies that have reported a link between TOEIC score and IDLE practice (Lee, 2019; Tagashira et al., 2010), IDLE practice and EIL perception (Lee \& Lee, 2019a, 2019b), and TOEIC score and EIL perception (Oliveri \& Tannenbaum, 2017), the model-IDLE practice mediates the relationship between TOEIC scores and perceptions of EIL-was constructed and tested using structural equation modelling. Expressed differently, it was hypothesised that students with higher TOEIC scores may engage more in IDLE activities, and that, in turn, increased engagement in IDLE activities may help students have more positive attitudes about EIL.

The role of IDLE practice as a potential mediator was assessed and confirmed based on Baron and Kenny's (1986) and MacKinnon and Dwyer's (1993) criteria. As shown in Figure 1, IDLE practice partially mediated the impact of TOEIC scores on EIL perceptions. The proposed model also demonstrated a good fit with the data set: $\chi^{2}$ divided by the value of degree of freedom was 1.19 , the comparative fit index was 0.98 , the normed fit index was 0.92 , and the goodness-of-fit index was 0.9 , and the root mean square of approximation was 0.05 (Hair et al., 1998).

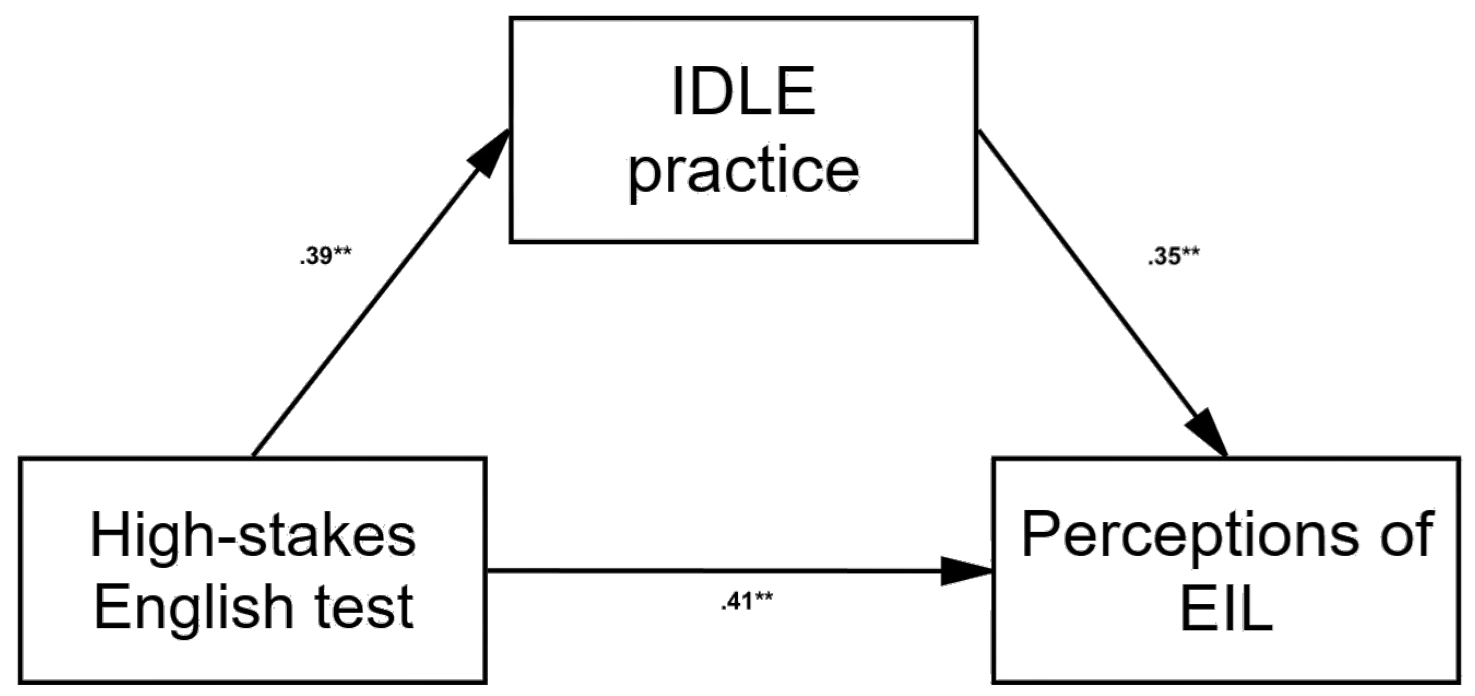

Figure 1. Model representing the mediating effect of IDLE practice 


\section{Discussion}

The hierarchical multiple regression analysis found that TOEIC scores and IDLE activities were significant predictors of EIL perceptions. Two insights can be drawn from this result. First, Korean EFL students who scored higher on TOEIC had more positive perceptions of other varieties of English and considered themselves more competent in using strategies for cross-cultural communication. It seems that TOEIC test takers were exposed to several English accents - although admittedly still limited to inner circle varieties of English - through test preparation materials (e.g., TOEIC practice books published by ETS), private TOEIC preparation programs, and actual tests, which may have helped increase their EIL perceptions (Hong et al., 2017; Jee \& Kim, 2013; Kang et al., 2019; Ke, 2019; Kubota, 2011). This result is also congruent with previous studies, which have shown that EFL students' exposure to distinct varieties of English is positively related to their perceptions of English varieties (Ates et al., 2015; Galloway \& Rose, 2013; Ke \& Cahyani, 2014; Ke \& Suzuki, 2011; Sung, 2018). Interestingly, EIL perceptions showed higher correlations with TOEIC than English speaking and productive vocabulary levels. Furthermore, speaking and productive vocabulary levels were not significant predictors of students' perceptions of EIL. These results suggest that the Korean students' EIL perceptions appeared to be more positively and significantly associated with their TOEIC scores than with English productive skills. It can be also implied that Korean English speakers with high levels of productive skills may not automatically hold positive attitudes about other varieties of English and may not communicate effectively in cross-cultural situations. It suggests that more proficient EFL speakers may not necessarily result in becoming competent users of English in cross-cultural communication settings. Additional data sources (e.g., interviews and observations) may be needed in order to delve deeper into the relationship between English productive skills and EIL perceptions.

Second, IDLE practice was positively related to students' perceptions of EIL, which is congruent with previous findings (Lee \& Lee, 2019a, 2019b). For example, students watched Indian films (e.g., 3 Idiots), practised English with Filipino English teachers via Skype, socialised with foreign friends from diverse countries on social media (e.g., KaKaoTalk and Facebook), and collaborated with other game players from various countries while playing massive multiplayer online role-playing games. It suggests that people who used technology (e.g., YouTube and social media) to appreciate a foreign culture and socialise with both native (e.g., American and Australian) and non-native English speakers (e.g., Japanese and Chinese) tended to hold more positive perceptions of English varieties and consider themselves as more competent users by employing cross-cultural communication strategies (e.g., behaving appropriately according to their interlocutors' cultural and linguistic background).

The structural equation modelling analysis further revealed that IDLE activities mediated the relationship between TOEIC scores and perceptions of EIL. This result suggests that students with higher TOEIC scores tended to engage more frequently in IDLE activities (e.g., learning about different cultures and interacting with diverse English speakers online), which enabled them to experience diverse accents and users of English and, subsequently, hold more positive perceptions of EIL. This result can be better understood by taking into account the unique position of TOEIC in Korean society. TOEIC is generally used as a critical criterion for recruiting and promoting Korean employees at major companies and government agencies (Choi, 2008; Hong et al., 2017; Kim, 2018). Thus, nearly $80 \%$ of the Korean undergraduate students who took part in Jee and Kim's (2013) study were reported as studying for the TOEIC for the purposes of graduation and employment. In this social milieu, most Korean universities offer mandatory TOEIC preparation courses (Hong et al., 2017; Kim, 2018). Students also intensively prepared for the TOEIC test through private cram schools (Choi, 2008) as well as self-study by means of various digital technologies (e.g., MP3 players, electronic dictionaries, smartphone applications, personal computers, and social media; Jee \& Kim, 2013). Therefore, it appears that a high-stakes English test such as TOEIC might have exerted a strong influence on Korean students' learning behaviours, such as studying TOEIC in IDLE environments. Subsequently, in the process of practising IDLE activities, Korean students appeared to encounter assorted English accents and speakers, which, in turn, was associated with their respective EIL perceptions (Lee \& Lee, 2019b). Based on the current data, however, it seems difficult to draw definite conclusions about which factors (e.g., TOEIC listening test input or IDLE activities prompted by the TOEIC test) might have more influenced students' higher EIL perceptions, which merits further research attention. 


\section{Pedagogical implications}

These results may offer some pedagogical implications for TESOL educators and test developers. First, TESOL professionals should recognise that IDLE activities and high-stakes international English tests, such as TOEIC, could play a positive role in enhancing EFL learners' EIL perceptions. Equally important, it is worth bearing in mind that EFL learners' higher levels of English productive skills may not automatically warrant their positive attitudes about other varieties of English and competence for adopting effective communication strategies in cross-cultural situations. In that regard, teachers can play a significant role, for example, as they discuss the current findings through lectures, so that students become more aware of the educational benefits stemming from IDLE activities and the TOEIC test. Hence, students can gain a balanced view of TOEIC's potential benefits (e.g., promoting IDLE activities and enhancing EIL perceptions) and limitations (e.g., a lack of validity; Choi, 2008; Kubota, 2011). Teachers can also encourage EFL students to develop and implement their own IDLE activities (e.g., fan fiction) based on their interests (e.g., Sherlock Holmes) and availability of digital devices (e.g., desktop computers or smartphones) and resources (e.g., https://www.fanfiction.net) (Sauro, 2017). As a result of these metacognitive forms of support, students who practise IDLE activities may experience different varieties of English in written or oral forms and are able to engage in cross-cultural communication with people who have different linguistic and cultural backgrounds. Consequently, this could lead to enhancing their EIL perceptions. In this regard, this learner-driven, IDLE-embedded EIL pedagogical suggestion could somehow complement the existing (teacher-led) EIL pedagogical model, which often takes place within a confined classroom environment.

In addition, to acknowledge the global use of English today (e.g., more heterogeneity in English norms), test developers such as ETS are encouraged to make continuous efforts to include various English accents into high-stakes international English listening tests, such as TOEIC. Although they are still inconclusive with regard to the effects of diverse accents on listeners' comprehension scores (Elder \& Harding, 2008; Major et al., 2002, 2005), some studies (e.g., Abeywickrama, 2013; Kang et al., 2019) have suggested that the use of native and non-native English pronunciations did not affect test takers' listening performances, so long as speech samples were highly comprehensible. Despite some challenges in implementing this idea due to a lack of empirical evidence and logistical issues (see Kang et al., 2019, p. 63, for further discussion), informed by the current results, it is hoped that test developers would take additional strides in reflecting on what constitutes authentic international English communication.

Although it is not directly informed by the current study, it is also worth noting that, in some local EFL contexts such as Korea and Taiwan, a high-stakes university entrance exam (e.g., American Englishoriented English listening questions) could exert a negative washback effect on EFL teachers' pedagogy (e.g., feeling pressured to teach American English accents) and students' EIL perceptions (e.g., considering American English as a correct version of English) (Ahn, 2014; H.-Y. T. Lai, 2008; Lee, Lee, \& Drajati, 2019). Thus, under such socio-educational systems, it also seems feasible for teachers to incorporate localised questions (e.g., EFL students are asked to discuss their local cultures in English) into school-based English tests so as to enhance their strategic and pragmatic EIL competence (Ke, 2019).

\section{Conclusion}

This study set out to examine the potential relationships among IDLE practice, a high-stakes international English test, English productive skills, and perceptions of EIL among Korean EFL undergraduate students. Results show that IDLE practice and TOEIC scores were significant predictors of EIL perceptions. Further analysis revealed that higher TOEIC scores might be linked to more positive perceptions of EIL due to more frequent engagement in IDLE activities. Although further study is needed, a variety of English accents used in the TOEIC listening tests as well as IDLE activities (through which students experience various English accents and users) seem advantageous for Korean EFL students in relation to their EIL perceptions. Based on current and previous results, this study provides some pedagogical implications for TESOL educators and test developers while taking into account Korea's specific educational context.

Nevertheless, there are a few limitations to the study. First, although data were collected from three major Korean cities, the sample size was relatively small in order to be representative of Korea and other EFL countries. Second, self-reported data may not accurately reflect participants' opinions due to responses 
based on perceived social desirability (van der Mortel, 2008). Third, it is unclear whether higher perceptions of EIL were influenced by various English accents used in the TOEIC listening tests or whether the students' engagement in IDLE activities was prompted by the social pressure associated with TOEIC tests. Thus, it would be necessary to investigate whether or how similar (e.g., EFL students in Taiwan) and different (e.g., ESL students in Australia) contextual environments may have influenced students' IDLE practices in connection with their EIL perceptions. Fourth, the subject needs further investigation as to why English productive skills (speaking and productive vocabulary knowledge) were not significantly associated with EIL perceptions.

In today's highly connected and globalised world, English users who can work competently across linguistically and culturally diverse environments are in great demand. Against this global backdrop, the current study reveals that IDLE practice and a high-stakes international English test, such as TOEIC, may play a positive role in enhancing EFL students' perceptions of EIL. Given that young EFL students are increasingly practising IDLE activities by employing a variety of media and that the TOEIC test exerts a strong influence on one's professional career in many EFL societies, it is hoped that this study may provide some pedagogical and research implications for English language teaching professionals. As a result, young English learners can become more competent English users as they continue to navigate their way across a span of diverse languages and cultures in both digital and non-digital contexts.

\section{References}

Abeywickrama, P. (2013). Why not non-native varieties of English as listening comprehension test input? RELC Journal, 44(1), 59-74. https://doi.org/10.1177/0033688212473270

Ahn, H. (2014). Teachers' attitudes towards Korean English in South Korea. World Englishes, 33(2), 195-222. https://doi.org/10.1111/weng.12081

Arndt, H. L., \& Woore, R. (2018). Vocabulary learning from watching YouTube videos and reading blog posts. Language Learning \& Technology, 22(3), 124-142. https://doi.org/10125/44660

Ates, B., Eslami, Z. R., \& Wright, K. L. (2015). Incorporating world Englishes into undergraduate ESL education courses. World Englishes, 34(3), 485-501. https://doi.org/10.1111/weng.12149

Baron, R. M., \& Kenny, D. A. (1986). The moderator-mediator distinction in social psychological research: Conceptual, strategic and statistical considerations. Journal of Personality and Social Psychology, 51(6), 1173-1182. https://doi.org/10.1037/0022-3514.51.6.1173

Benson, P. (2015). Commenting to learn: Evidence of language and intercultural learning in comments on YouTube videos. Language Learning \& Technology, 19(3), 88-105. Retrieved from http://1lt.msu.edu/issues/october2015/benson.pdf

Bozoglan, H., \& Gok, D. (2017). Effect of mobile-assisted dialect awareness training on the dialect attitudes of prospective English language teachers. Journal of Multilingual and Multicultural Development, 38(9), 772-787. https://doi.org/10.1080/01434632.2016.1260572

Chen, G.-M. (2012). The impact of new media on intercultural communication in global context. China Media Research, 8(2), 1-10. Retrieved from http://www.wwdw.chinamediaresearch.net/index.php/back-issues?id=54

Choi, I.-C. (2008). The impact of EFL testing on EFL education in Korea. Language Testing, 25(1), 3962. https://doi.org/10.1177/0265532207083744

Cole, J., \& Vanderplank, R. (2016). Comparing autonomous and class-based learners in Brazil: Evidence for the present-day advantages of informal, out-of-class learning. System, 61, 31-42. https://doi.org/10.1016/j.system.2016.07.007

Educational Testing Service. (2018a). 2017 report on test takers worldwide. Retrieved from https://www.ets.org/s/toeic/pdf/2017-report-on-test-takers-worldwide.pdf

Educational Testing Service. (2018b). TOEFL iBT ${ }^{\circledR}$ test: Independent speaking rubrics. Retrieved from https://www.ets.org/s/toefl/pdf/toefl speaking rubrics.pdf

Educational Testing Service. (2018c, January 19). TOEIC ${ }^{\circledR}$ listening and reading test to receive updates. Retrieved from https://news.ets.org/press-releases/toeic-listening-reading-test-receive-updates/

Elder, C., \& Harding, L. (2008). Language testing and English as an international language: Constraints and contributions. Australian Review of Applied Linguistics, 31(3), 34.31-34.11. https://doi.org/10.2104/aral0834

Finch, J. F., \& West, S. G. (1997). The investigation of personality structure: Statistical models. Journal of Research in Personality, 31(4), 439-485. https://doi.org/10.1006/jrpe.1997.2194 
Friedman, T. (2005). It is a flat world, after all. In J. T. Roberts \& A. B. Hite (Eds.), The globalization and development reader: Perspectives on development and global change (pp. 247-256). Oxford, United Kingdom: Oxford Press.

Galloway, N., \& Rose, H. (2013). They envision going to New York, not Jakarta: The differing attitudes toward ELF of students, teaching assistants, and instructors in an English-medium business program in Japan. Journal of English as a Lingua Franca, 2(2), 229-253. https://doi.org/10.1515/jelf-2013$\underline{0014}$

Galloway, N., \& H. Rose. (2015). Introducing global Englishes. Abingdon, United Kingdom: Routledge.

Galloway, N., \& Rose, H. (2018). Incorporating global Englishes into the ELT classroom. ELT Journal, 72(1), 3-14. https://doi.org/10.1093/elt/ccx010

Gillham, D., Bellis, A. D., Xiao, L., Willis, E., Harrington, A., Morey, W., \& Jeffers, L. (2018). Using research evidence to inform staff learning needs in cross-cultural communication in aged care homes. Nurse Education Today, 63, 18-23. https://doi.org/10.1016/j.nedt.2018.01.007

Godwin-Jones, R. (2018). Chasing the butterfly effect: Informal language learning online as a complex system. Language Learning \& Technology, 22(2), 8-27. https://doi.org/10125/44643

Hair, J., Anderson, R., Tatham, R., \& Black, W. (1998). Multivariate data analysis (5th ed). Upper Saddle River, NJ: Prentice-Hall International.

Hong, S., Kim, S.-H., \& Bae, S.-Y. (2017). A study on convergence factors related with academic burnout of students in health majors in studying for TOEIC. Journal of Digital Convergence, 15(6), 315-327. https://doi.org/10.14400/JDC.2017.15.6.315

Hsu, S.-Y., \& Beasley, R. E. (2019). The effects of international email and Skype interactions on computer-mediated communication perceptions and attitudes and intercultural competence in Taiwanese students. Australasian Journal of Educational Technology, 35(1), 149-162. https://doi.org/10.14742/ajet.4209

In'nami, Y., \& Koizumi, R. (2017). Using EIKEN, TOEFL, and TOEIC to award EFL course credits in Japanese universities. Language Assessment Quarterly, 14(3), 274-293. https://doi.org/10.1080/15434303.2016.1262375

International Communication Foundation. (2005, October 1). 판문점 공동경비구역 (JSA) TOEIC 정기시험실시: 영어 실력은 군 임무 완수를 위한 ‘전투력, 입니다! [TOEIC test took place in the Joint Security Area (JSA): English skill are the "combat ability" to complete military missions. TOEIC Newsletter. Retrieved from http://upsisa.ybmsisa.com/si/exam ybmsisa com/newsletter/pdffile/30 sub3.pdf

Jee, S., \& Kim, H.-C. (2013). Understanding English learners preparing for TOEIC and their information technology usage practice in Korea. International Journal of Multimedia and Ubiquitous Engineering, 8(5), 93-104. https://doi.org/10.14257/ijmue.2013.8.5.10

Jenkins, J. (2005). Implementing an international approach to English pronunciation: The role of teacher attitudes and identity. TESOL Quarterly, 39(3), 535-543. https://doi.org/10.2307/3588493

Jensen, S. H. (2017). Gaming as an English language learning resource among young children in Denmark. CALICO Journal, 34(1), 1-19. https://doi.org/10.1558/cj.29519

Jurkovič, V. (2019). Online informal learning of English through smartphones. System, 80, $27-37$. https://doi.org/10.1016/j.system.2018.10.007

Kachru, B. B. (1985). Standards, codification and sociolinguistic realism: The English language in the Outer Circle. In R. Quirk \& H. G. Widdowson (Eds.), English in the world: Teaching and learning the language and literatures (pp. 11-30). Cambridge, United Kingdom: Cambridge University Press.

Kang, O., Moran, M., \& Thomson, R. (2019). The effects of international accents and shared first language on listening comprehension tests. TESOL Quarterly, 53(1), 56-81. https://doi.org/10.1002/tesq.463

Ke, I.-C. (2019). Has English been increasingly tested as an international language? Evidence from 19562016. Language, Culture and Curriculum, 32(2), 191-206. https://doi.org/10.1080/07908318.2018.1512609

Ke, I.-C., \& Cahyani, H. (2014). Learning to become users of English as a Lingua Franca (ELF): How ELF online communication affects Taiwanese learners' beliefs of English. System, 46, $28-38$. https://doi.org/10.1016/j.system.2014.07.008

Ke, I.-C., \& Suzuki, T. (2011). Teaching global English with NNS-NNS online communication. The Journal of Asia TEFL, 8(2), 169-188. Retrieved from http://www.asiatefl.org/main/download_pdf.php?i=139\&c=1419302749\&fn=8_2_08.pdf

Kim, J. O. (2018). Ongoing speaking anxiety of Korean EFL learners: Case study of a TOEIC intensive 
program. The Journal of Asia TEFL, 15(1), 17-31. Retrieved from http://www.asiatefl.org/main/download pdf.php?i=551\&c=1522400274\&fn=15 1 02.pdf

Kobayashi, Y. (2018). The neo-liberal notion of global language skills vs. monolingual corporate culture: Co-existence or rivalry? Journal of Multilingual and Multicultural Development, 39(8), 729-739. https://doi.org/10.1080/01434632.2018.1438445

Kubota, R. (2011). Questioning linguistic instrumentalism: English, neoliberalism, and language tests in Japan. Linguistics and Education, 22(3), 248-260. https://doi.org/10.1016/j.linged.2011.02.002

Kusyk, M. (2017). The development of complexity, accuracy and fluency in L2 written production through informal participation in online activities. CALICO Journal, 34(1), 75-96. https://doi.org/10.1558/cj.29513

Lai, C. (2017). Autonomous language learning with technology beyond the classroom. New York, NY: Bloomsbury Publishing.

Lai, C. (2019). The influence of extramural access to mainstream culture social media on ethnic minority students' motivation for language learning. British Journal of Educational Technology, 50(4), 19291941. https://doi.org/10.1111/bjet.12693

Lai, C., Zhu, W., \& Gong, G. (2015). Understanding the quality of out-of-class English learning. TESOL Quarterly, 49(2), 278-308. https://doi.org/10.1002/tesq.171

Lai, H.-Y. T. (2008). English as an international language? Taiwanese university teachers' dilemma and struggle... English Today, 24(3), 39-45. https://doi.org/10.1017/S0266078408000278

Laufer, B., \& Nation, P. (1999). A vocabulary-size test of controlled productive ability. Language Testing, 16(1), 33-51. chttps://doi.org/10.1080/01434632.2018.1438445

Lee, J. S. (2019). Quantity and diversity of informal digital learning of English. Language Learning \& Technology, 23(1), 114-126. https://doi.org/10125/44675

Lee, J. S., \& Dressman, M. (2018). When IDLE hands make an English workshop: Informal digital learning of English and language proficiency. TESOL Quarterly, 52(2), 435-445. https://doi.org/10.1002/tesq.422

Lee, J. S., \& Lee, K. (2019a). Informal digital learning of English and English as an international language: The path less traveled. British Journal of Educational Technology, 50(3), 1447-1461. https://doi.org/10.1111/bjet.12652

Lee, J. S., \& Lee, K. (2019b). Perceptions of English as an international language by Korean Englishmajor and non-English-major students. Journal of Multilingual and Multicultural Development, 40(1), 76-89. https://doi.org/10.1080/01434632.2018.1480628

Lee, J. S., Lee, K., \& Drajati, N. A. (2019). Preservice English teachers' perceptions of English as an international language in Indonesia and Korea. Journal of Multilingual and Multicultural Development, 40(3), 230-243. https://doi.org/10.1080/01434632.2018.1503669

MacKinnon, D. P., \& Dwyer, J. H. (1993). Estimating mediated effects in prevention studies. Evaluation Review, 17(2), 144-158. https://doi.org/10.1177/0193841X9301700202

Major, R. C., Fitzmaurice, S. F., Bunta, F., \& Balasubramanian, C. (2002). The effects of nonnative accents on listening comprehension: Implications for ESL assessment. TESOL Quarterly, 36(2), 173190. https://doi.org/10.2307/3588329

Major, R. C., Fitzmaurice, S. F., Bunta, F., \& Balasubramanian, C. (2005). Testing the effects of regional, ethnic, and international dialects of English on listening comprehension. Language Learning, 55(1), 37-69. https://doi.org/10.1111/j.0023-8333.2005.00289.x

Matsuda, A. (2002). "International understanding" through teaching World Englishes. World Englishes, 21(3), 436-440. https://doi.org/10.1111/1467-971X.00262

Matsuda, A. (Ed.). (2012). Principles and practices of teaching English as an international language. Bristol, United Kingdom: Multilingual Matters.

Matsuda, A. (Ed.). (2017). Preparing teachers to teach English as an International Language. Bristol, United Kingdom: Multilingual Matters.

Matsuda, A. (2018). Is teaching English as an international language all about being politically correct? RELC Journal, 49(1), 24-35. https://doi.org/10.1177/0033688217753489

McKay, S. L. (2002). Teaching English as an international language. Oxford, United Kingdom: Oxford University Press.

McKay, S. L. (2018). English as an international language: What it is and what it means for pedagogy. RELC Journal, 49(1), 9-23. https://doi.org/10.1177/0033688217738817

Oliveri, M. E., \& Tannenbaum, R. J. (2017). Insights into using TOEIC test scores to inform human resource management decisions. ETS Research Report Series, 1, 1-7.

https://doi.org/10.1002/ets2.12177 
Park, B. (2012). Does the PVLT provide an accurate measure of productive vocabulary knowledge? English Teaching, 67(2), 159-182. https://doi.org/10.15858/engtea.67.2.201207.159

Park, J. S.-Y. (2011). The promise of English: Linguistic capital and the neoliberal worker in the South Korean job market. International Journal of Bilingual Education and Bilingualism, 14(4), 443-455. https://doi.org/10.1080/13670050.2011.573067

Popescu, F., \& Warmenhoven, R. (2019). Use of technology and virtual communication via global virtual teams at Arnhem business school. In J. I. Kantola, S. Nazir, \& T. Barath (Eds.), Advances in human factors, business management and society (pp. 239-248). Cham, Switzerland: Springer.

Richards, J. C. (2015). The changing face of language learning: Learning beyond the classroom. RELC Journal, 46(1), 5-22. https://doi.org/10.1177/0033688214561621

Rohrbach, J. (2018, May 10). How new technologies are changing language learning, for better and worse. Forbes. Retrieved from https://www.forbes.com/sites/forbesnycouncil/2018/05/10/how-newtechnologies-are-changing-language-learning-for-better-and-worse/\#15a59c7ca178

Rosen, J., Spatz, E. S., Gaaserud, A. M. J., Abramovitch, H., Weinreb, B., Wenger, N. S., \& Margolis, C. Z. (2004). A new approach to developing cross-cultural communication skills. Medical Teacher, 26(2), 126-132. https://doi.org/10.1080/01421590310001653946

Sauro, S. (2017). Online fan practices and CALL. CALICO Journal, 34(2), 131-146. https://doi.org/10.1558/cj.33077

Sauro, S., \& Zourou, K. (2019). What are the digital wilds? Language Learning \& Technology, 23(1), 17. https://doi.org/10125/44666

Sharifian, F. (2009). English as an international language: Perspectives and pedagogical issues. Bristol, United Kingdom: Multilingual Matters.

Shrout, P. E., \& Fleiss, J. L. (1979). Intraclass correlations: Uses in assessing rater reliability. Psychological Bulletin, 86(2), 420-428. https://doi.org/10.1037//0033-2909.86.2.420

Smith, L. (1976). English as an international auxiliary language. RELC Journal, 7(2), 38-43.

https://doi.org/10.1177/003368827600700205

Sockett, G., \& Toffoli, D. (2012). Beyond learner autonomy: A dynamic systems view of the informal learning of English in virtual online communities. ReCALL, 24(2), 138-151. https://doi.org/10.1017/S0958344012000031

Sundqvist, P. (2019). Commercial-off-the-shelf games in the digital wild and L2 learner vocabulary. Language Learning \& Technology, 23(1), 87-113. https://doi.org/10125/44674

Sundqvist, P., \& Sylvén, L. K. (2014). Language-related computer use: Focus on young L2 English learners in Sweden. ReCALL, 26, 3-20. https://doi.org/10.1017/S0958344013000232

Sundqvist, P., \& Sylvén, L. K. (2016). Extramural English in the teaching and learning: From theory and research to practice. London, United Kingdom: Palgrave Macmillan.

Sung, C. C. M. (2018). Out-of-class communication and awareness of English as a Lingua Franca. ELT Journal, 72(1), 15-25. https://doi.org/10.1093/elt/ccx024

Sylvén, L. K., \& Sundqvist, P. (2017). Computer-Assisted Language Learning (CALL) in extracurricular/extramural contexts. CALICO Journal, 34(1), i-iv. https://doi.org/10.1558/cj.31822

Tanghe, S. (2014). Integrating World Englishes into a university conversation class in South Korea. English Today, 30(2), 18-23. https://doi.org/10.1017/S026607841400008X

Tagashira, K., Isoda, T., Maeda, H., Enokida, K., Davies, W., Fraser, S., . . Tsuido, K. (2010). Effects of different types of out-of-class learning on TOEIC score gains. Retrieved from http://www.iibcglobal.org/library/redirect_only/library/toeic_data/toeic_en/pdf/newsletter/5_E.pdf

van der Mortel, T. F. (2008). Faking it: Social desirability response bias in self-report research. Australian Journal of Advanced Nursing, 25(4), 40-48. Retrieved from https://www.ajan.com.au/archive/Vol25/Vol_25-4_vandeMortel.pdf

Wang, C.-M. (2011). Instructional design for cross-cultural online collaboration: Grouping strategies and assignment design. Australasian Journal of Educational Technology, 27(2), 243-258. https://doi.org/10.14742/ajet.968

$\mathrm{Xu}, \mathrm{Z}$. (2017). Developing metacultural writing competence for online intercultural communication: Implications for English language teaching. TESL-EJ, 20(4), 1-9. Retrieved from http://www.teslej.org/wordpress/issues/volume20/ej80/ej80a4/ 
Corresponding author: Ju Seong Lee, jslee@eduhk.hk

Copyright: Articles published in the Australasian Journal of Educational Technology (AJET) are available under Creative Commons Attribution Non-Commercial No Derivatives Licence (CC BYNC-ND 4.0). Authors retain copyright in their work and grant AJET right of first publication under CC BY-NC-ND 4.0.

Please cite as: Lee, J. S. (2020). The role of informal digital learning of English and a high-stakes English test on perceptions of English as an international language. Australasian Journal of Educational Technology, 36(2), 155-168. https://doi.org/10.14742/ajet.5319 